\title{
A ARTE SOB A PERSPECTIVA DO MARXISMO: UMA ATIVIDADE HUMANA POTENCIALMENTE HUMANIZADORA
}

\author{
ARTE EM LA PERSPECTIVA DEL MARXISMO: UMA ACTIVIDAD HUMANA \\ POTENCIALMENTE HUMANIZADORA
}

\section{THE ART FROM THE PERSPECTIVE OF MARXISM: A POTENTIALLY HUMANIZING HUMAN ACTIVITY}

DOI: http://dx.doi.org/10.9771/gmed.v11i3.33760

\author{
Mércia Santana Mathias ${ }^{1}$
}

Luciana Cristina Salvatti Coutinho ${ }^{2}$

\begin{abstract}
Resumo: Esse ensaio trata-se da discussão acerca dos escritos de Karl Marx e de outros autores sob a perspectiva do marxismo, buscando apreender os principais preceitos marxistas que podem ter relação com a arte. O ponto de partida é a obra de Ernst Fischer (1959) intitulada "A necessidade da arte". É uma pesquisa do tipo qualitativa bibliográfica exploratória. Conclui-se que a arte deveria ser abordada em sua dimensão cultural, independentemente da forma de expressão utilizada. Sob a perspectiva do marxismo é possível observar as bases materiais da existência humana que corroboram o princípio de que a arte sempre esteve presente na histórica trajetória da existência humana, com diferentes sentidos.
\end{abstract}

Palavras-chave: Arte. Cultura. Marxismo.

Resumen: Este ensayo aborda la discusión sobre los escritos de Karl Marx y otros autores desde la perspectiva del marxismo, buscando comprender los principales preceptos marxistas que pueden estar relacionados con el arte. El punto de partida es el trabajo de Ernst Fischer (1959) titulado "La necesidad de arte". Es una investigación bibliográfica exploratoria cualitativa. Se concluye que el arte debe abordarse en su dimensión cultural, independientemente de la forma de expresión utilizada. Desde la perspectiva del marxismo es posible observar las bases materiales de la existencia humana que corroboran el principio de que el arte siempre ha estado presente en la trayectoria histórica de la existencia humana, con diferentes significados.

Palabras clave: Arte. Cultura. Marxismo.

Abstract: This essay is about the discussion of the writings of Karl Marx and other authors from the perspective of Marxism, aiming to understand the main Marxist precepts in relation to art. The point of departure is the work of Ernst Fischer (1959) entitled "The necessity of the art". It is a research of the qualitative exploratory bibliographic type. We conclude that art should be approached in its cultural dimension, regardless of the form of expression used. From the perspective of original Marxism it is possible to observe the material bases of human existence that corroborate the principle that art has always been present in the historical trajectory of human existence, with different meanings.

Keywords: Art. Culture. Marxism.

\section{O legado de Marx em relação à arte}

$\mathrm{Na}$ contemporaneidade existe um consenso entre os estudiosos do filósofo Karl Marx (DUARTE e ABREU, 2019; COTRIM, 2012; FISCHER, 1959) sobre o seu legado na área do 
conhecimento artístico. Estes são unânimes em afirmar que dentre as suas obras já conhecidas, a arte não aparece como temática principal. Contudo, de acordo com Cotrim (2012, p. 14), Marx refere-se à arte em várias passagens de seus escritos, porém, “[...] não se trata de ilustrar leis gerais com casos pinçados da literatura, mas de concretizar (...) atributos e relações humanas operadas pela generalização do nexo do dinheiro".

Quando Marx discorre sobre os estágios do desenvolvimento social da humanidade, especificamente a fase da infância, segundo nos aponta Kosik (1959, p. 16) “[...] Marx descreveu a epopéia como a forma artística típica de uma sociedade ainda não-desenvolvida". Para Marx, o ponto mais significativo não era a compreensão de a epopéia grega3 estar relacionada a certa forma de desenvolvimento social, mas o fascínio que esta arte ainda exerce.

Outro argumento sobre os escritos de Marx que perpassam a arte diz respeito ao seu caráter antropomórfico. A antropomorfia refere-se à atribuição de sentimentos e comportamentos tipicamente humanos imputados a seres imaginários, como por exemplo, os deuses e heróis. Cotrim (2012, p. 18) expõe o seguinte,

[...] a mitologia é, assim, criada espontaneamente pelo povo, como modo específico de apreender seu mundo natural e social. Nela, as forças da natureza e relações sociais são plasmadas na imaginação popular, de modo que se trata de uma apreensão espontaneamente imaginativa do mundo.

Através da observação da forma material da existência humana, Marx introduz muitas reflexões e idéias nítidas sobre o significado universal da arte, a épica grega, a mitologia, gêneros poéticos e a literatura. A correlação entre a arte e a sociedade é contextualizada por Marx visando estabelecer entre infra-estrutura social e a superestrutura artística um nexo de causalidade. São exemplificações concretas que surgem no sentido de esclarecimentos sobre a relação desigual entre o desenvolvimento da produção material e o fazer artístico. A intenção é “[...] elucidar e particularizar processos históricos” (COTRIM, 2012, p. 14).

A idéia é que as várias formas da existência e das relações humanas - as políticas, estatais, jurídicas, familiares, a cultura, a arte etc - embora se enraízem, em cada período histórico e em cada localidade, no modo como ali se reproduzem a vida e os meios de vida, não necessariamente acompanham num sentido progressivo o avanço produtivo, ou lhe são paralelas (COTRIM, 2012, p. 14).

Marx decididamente se opõe a idéia do senso-comum de que as formas de arte mais antigas estejam aquém das mais atuais. Desta forma, uma dada sociedade mais desenvolvida, não necessariamente produz uma forma de arte compatível com seu grau de desenvolvimento. No caso da arte grega, especificamente a epopéia, considerando-se o nível de desenvolvimento histórico e social da época, esta conseguiu exceder as expectativas, quando comparada aos períodos históricos conseguintes.

$\mathrm{Na}$ arte, é sabido que determinadas épocas de florescimento não guardam nenhuma relação com o desenvolvimento geral da sociedade, nem, portanto, com o da base material, que é, por assim dizer, a ossatura de sua organização. Por exemplo, os gregos comparados com os modernos [...] (MARX, 2011, p. 62-63). 
Portanto, é fato que Marx não escreveu especificamente sobre a arte, mas pelos registros que efetuou, percebe-se que nos seus escritos a arte é como o esboço no enquadramento das considerações que apontam que as atividades humanas já estiveram intrinsecamente relacionadas ao fazer artístico.

\section{Arte e marxismo: aproximações segundo Althusser}

Dentre os escritores marxistas, foi o filósofo Louis Althusser (1968) que escreveu de forma contundente sobre as aproximações da arte em relação à filosofia de Marx. Althusser (1968, p. 54), ao expor as idéias de Bertolt Brecht acerca do teatro, aponta as relações do marxismo com a arte:

[...] o que me impressiona imensamente, é um tipo de paralelismo entre a revolução de Brecht no teatro e a revolução de Marx na filosofia. Brecht não era filósofo, dir-se-á, e os professores de filosofia não vão buscar em Brecht lições de filosofias. Por quê? Porque ele não escreveu um livro de filosofia, ele não elaborou um sistema filosófico, nem tinha um discurso teórico filosófico. O próprio Brecht afirmava que era leigo em filosofia. Os professores de filosofia não têm razão. Pois, Brecht compreendeu muito bem o essencial da revolução filosófica de Marx. Ele a compreendeu em 'estado prático', não como um discurso teórico, mas como chamarei de sua 'prática teatral'.

É significativo que Althusser tenha escolhido escrever sobre uma das formas artísticas das mais expressivas, porquanto o teatro pode comportar em si mesmo todas as outras formas artísticas. Mais significativo ainda é a escolha recair sobre Brecht, que já em 1929, escrevia: “O futuro do teatro está na filosofia”. Althusser (1968, p. 52) ainda aponta que na obra de Brecht intitulada Un entretien socialiste (1953), o mesmo anunciava que: "O princípio que quis aplicar ao teatro, é o de que não basta se contentar em dar uma interpretação do mundo; é preciso também transformá-lo”.

Infelizmente, o texto de Althusser (1968) sobre Brecht e o teatro se encerra evidentemente inacabado. Mas não sem antes esboçar citações das ideias de Aristóteles (o teatro é uma forma de catarse); e Freud (a arte é um triunfo fictício). Evidentemente Althusser traduz estes raciocínios e escreve "[...] no teatro, o espectador se dá o prazer de se ver brincar com fogo, ou que o fogo não está nele, mas nos outros, de todo modo para estar seguro de que não há fogo nele”, e conclui que,

Se quisermos saber por que o teatro diverte, é necessário levar em conta esse tipo muito particular de prazer: aquele de brincar com fogo sem perigo, com essa dupla condição: 1. É um fogo sem perigo porque ele está sobre a cena, e porque a peça de teatro apaga sempre o fogo, e 2. Quando há fogo, este está sempre no vizinho (ALTHUSSER, 1968, p. 62).

Qual seria então a função da arte? Entreter, divertir, relaxar? Um recurso para ostentação de privilégio social? Tais perguntas não poderão ser respondidas se não houver uma reflexão. Neste sentido, Kosik (1969, p. 21) esclarece que,

Como as coisas não se mostram ao homem diretamente tal qual são e como o homem não tem a faculdade de ver as coisas diretamente na sua essência, a humanidade faz um détour para conhecer as coisas e a sua estrutura. Justamente porque tal détour é o único caminho acessível ao homem para chegar à verdade, periodicamente a humanidade tenta poupar-se o trabalho desse desvio e procura diretamente a essência das coisas (o misticismo é justamente a impaciência do homem em conhecer a verdade). Com isso corre o perigo de perder-se ou de ficar no meio do caminho, enquanto percorre tal desvio. 
Segundo Fischer (1959, p. 13), o ser humano tem a tendência de considerar comum algo que na realidade é um fenômeno surpreendente, vivenciamos vários momentos onde a arte surge, mas geralmente sem a devida atenção.

Se fosse da natureza do homem o não ser ele mais do que um indivíduo, tal desejo seria absurdo e incompreensível, porque então como indivíduo ele já seria um todo pleno, já seria tudo o que era capaz de ser. O desejo do homem de se desenvolver e completar indica que ele é mais do que um indivíduo. Sente que só pode atingir a plenitude se se apoderar das experiências alheias que potencialmente lhe concernem, que poderiam ser dele. E o que um homem sente como potencialmente seu inclui tudo aquilo de que a humanidade, como um todo, é capaz. A arte é o meio indispensável para essa união do indivíduo com o todo; reflete a infinita capacidade humana para a associação, para a circulação de experiências e idéias.

Portanto, a arte é uma forma de objetivação do ser humano que almeja exceder os limites da sua própria existência e tornar social a sua individualidade. Esta individualidade manifesta é fruto da compreensão de si mesmo através da observação da realidade constituída coletivamente, ou seja, de "alguma coisa que, sendo exterior a ele mesmo (o homem), não deixe de lhe ser essencial" (FISCHER, 1959, p. 13).

\section{O sentido da arte para a humanidade}

A arte nos primórdios da humanidade pouco tinha do sentido que temos na contemporaneidade. A arte neste contexto histórico é a atividade que desempenha a importante função de conduzir a humanidade na sua luta cotidiana pela sobrevivência.

Através da observação das leis da natureza, com os conhecimentos até então alcançados, o homem se apropria da arte na intenção de obter maior domínio sobre a natureza e, com isto, enriquecer a sua própria existência no convívio da coletividade, através de uma ação efetiva: o trabalho.

O homem se apodera da natureza transformando-a. O trabalho é a transformação da natureza. O homem também sonha com um trabalho mágico que transforme a natureza, sonha com a capacidade de mudar os objetos e dar-lhes nova forma por meios mágicos. Trata-se de um equivalente na imaginação àquilo que o trabalho significa na realidade. O homem é, por principio, um mágico (FISCHER, 1959, p. 21).

E o que é trabalho? Fischer (1959, p. 21) expõe conceitualmente, a partir de Marx n'O Capital:

O processo do trabalho é [...] atividade deliberada [...] para a adaptação das substâncias naturais aos desejos humanos; é a condição permanente imposta pela natureza à vida humana e, por conseguinte, independe das formas da vida social - ou, melhor, é comum a todas as formas sociais.

Como é muito comum a assertiva de que arte é tão antiga quanto o homem, procurando por referências, encontramos em Fischer (1959, p. 21) a afirmação de que "a arte é quase tão antiga quanto o homem". O que se faz entender com a expressão deliberada de "quase" é que existe algo ainda mais anterior a arte. $\mathrm{Na}$ continuidade da exposição, o autor esclarece que a arte "é uma forma de trabalho, e o trabalho é uma característica do homem".

A coletividade humana emergente, reproduzindo o mesmo processo incessantemente, permite ao trabalho coletivo uma regularidade rítmica registrada pelos sentidos. Este processo coletivo de trabalho 
necessita de organização interna que se apoia através de canções que são entoadas durante a atividade coletiva. Estes "cantos de trabalho", como expõe Fischer (1959, p. 39), "exerce certo efeito mágico na vinculação dos indivíduos ao grupo, o indivíduo preserva o sentido coletivo mesmo se está trabalhando fora dele". Um argumento exposto por Kosik (1969, p. 74) aponta a veracidade neste princípio, assegurando que, "[...] pelo simples fato de existir, o homem é um ser social".

O processo histórico da sociedade tribal comunitária foi um percurso permeado por relações pacíficas de trocas, retribuições, dádivas e oferta da produção excedente, ou seja, de tudo que ultrapassava o limite do necessário. A produção artística serviria de intercâmbio entre comunidades distintas, o que potencializava as inter relações amistosas. Estas são, pois, as formas mais primitivas da idéia de riquez̧a, a riqueza social. Podemos perceber que estas relações consideradas de colaboração recíproca, conforme explicita Harnecker (1971, p. 51) "se estabelecem quando existe uma propriedade social dos meios de produção e quando nenhum setor da sociedade vive da exploração de outro setor". No sentido de colaboração, neste contexto, também estavam as manifestações artísticas. O homem então vivia e produzia a arte no seu contexto histórico e social desde tenra idade, portanto, a arte é uma das primeiras formas de posse do ser humano, se constituindo um saber fazer e viver na comunidade a qual pertence.

Percebe-se que após a dissolução das comunidades primitivas e a instituição de um novo modelo de sociedade, a arte ganha consequentemente outros sentidos:

Esta produção que tem origem no objeto útil e que dele se descola, a ele retorna à medida que se desenvolve o processo de divisão e complexificação do trabalho. À medida que todo consumo se torna privado e que todo produto se torna mercadoria, $\mathrm{O}$ objeto artístico tem que se submeter à lógica do capital (TROJAN, 1996, p. 92).

Partindo do pressuposto do valor social da arte, esta não pode ser comparada ao conceito de mercadoria no sentido econômico e político, pois quando Marx (2008, p. 51-52) discute sobre o tema mercadoria, esclarece que:

A mercadoria, na linguagem dos economistas ingleses, é, em primeiro lugar 'uma coisa qualquer, necessária, útil ou agradável à vida', objeto de necessidades humanas, meio de existência na mais alta acepção da palavra. A forma sob a qual a mercadoria é um valor de uso confunde-se com sua existência material tangível.

A discussão de Marx (idem, p. 52) sobre mercadoria se inicia com a distinção entre o valor de uso e o valor de troca, e esclarece que "o valor de uso não tem valor senão para uso, e não adquire realidade senão no processo de consumo". Ademais o valor de uso pode apresentar um caráter estético, sem necessariamente ser mercadoria, portanto, toda mercadoria é valor de uso, mas nem todo valor de uso é mercadoria. $\mathrm{Na}$ observância da trajetória da humanidade, as experiências ensinam que o caráter mercadológico da arte é algo bem mais recente da nossa história.

\section{A magia da arte}

A arte não é uma atividade humana idêntica ao trabalho e suas relações de produção; a arte é uma forma de trabalho no sentido "mágico". Este sentido mágico que surge da capacidade do ser humano antever as causas finais de fenômenos naturais, Hartley (1992, p. 3) diz que é a condição de "[...] explicar 
retrospectivamente tudo o que aconteceu antes". A arte é uma forma de resposta ao potencial humano neste sentido mágico.

E sobre o preceito da teleologia como doutrina das causas finais, é importante enfatizar que de forma alguma esta trata de conclusões precipitadas. Para Johnson (2005, p. 1), a teleologia se baseia em “[...] uma explicação científica e de causalidade". Obviamente na antiguidade, sob a ausência da ciência, esta capacidade teleológica estava intimamente relacionada à magia, e concedia a certos indivíduos e grupos uma aura de divindade.

$\mathrm{Na}$ contemporaneidade a teleologia se divide em duas grandes vertentes: Aristotélica e a Darwinista, abrangendo várias questões, mas principalmente as de ordem teológicas, filosóficas e biológicas.

Um estudo minucioso da teleologia de Aristóteles pode nos dizer muito sobre a
filosofia de Aristóteles, sobre a filosofia grega em geral, e até sobre os problemas
filosóficos, científicos e éticos contemporâneos da explicação científica da causalidade
[...] em um estudo abrangente recente da causalidade e sua explicação na filosofia grega,
abrangendo mais de um milênio, a teleologia é considerada a questão central. A
teleologia é por muitos considerada a chave do pensamento de Aristóteles
(JOHNSON, 2005, p. 1).

Sobre a magia, é muito interessante o argumento exposto por Österblom et al (2007): "a magia ensinou uma importante lição à ciência: o quanto nosso cérebro pode ser enganado”. Enquanto não havia meios propícios para explicar objetivamente fenômenos mais complexos sem recorrer à experiência, a arte exercia convenientemente esta função.

A arte também serviu à transformação da natureza e dos objetos para dar-lhes uma nova forma; pela arte há a possibilidade de reflexão sobre a própria realidade como ponto de partida. Através da arte o homem é capaz de sonhar com alternativas de explorar outros possíveis meios de atingir seus objetivos, atendendo as necessidades que se apresentam no cotidiano. Lukács (1968) defende que a arte é inata a todo ser humano, apesar de que algumas atividades favorecem o seu desenvolvimento, outras nem tanto. Aqui se faz necessária a compreensão de que a dimensão de artista pode abranger o pintor de paredes, arquiteto, marceneiro, escritor, etc. Portanto, mudam-se os instrumentos, as técnicas e os materiais em função de cada necessidade, mas o princípio é que a arte é uma capacidade humana, é inerente a todos os seres humanos. No percurso histórico, esta capacidade de ver-se como artista vai esvanecendo gradativamente, porquanto a arte passa a ser uma disciplina a parte, uma especialização, perdendo seu caráter de transversalidade. Mas quando ou por que isto ocorre? Trojan (1996, p. 94) expõe o seguinte: “[...] a propriedade privada se opõe ao caráter universal da arte; aquilo que tem a função de comunicar através de imagens e sons a percepção do homem e sobre si mesmo, é incompatível com a restrição do consumo individual e privado".

$\mathrm{Na}$ antiguidade a parte excedente da produção inicialmente tinha valor de uso, pois eram produtos que visavam atender às necessidades imediatas de subsistência do ser humano. São mercadorias não-acumulativas, enquanto são perecíveis. Em dado momento histórico, configura-se, então, o valor de mercadoria, este sim, passível de acumulação. 
Os produtos supérfluos convertem-se em produtos permutáveis ou mercadorias. A forma adequada de existência desse supérfluo é o ouro ou a prata; é a primeira forma sob qual a riqueza é fixada como riqueza social abstrata. As mercadorias podem ser conservadas tanto sob a forma de ouro e de prata, isto é, na matéria do dinheiro, quando também o ouro e a prata são riquezas sob forma preservada (MARX, 2004, p. 163).

$\mathrm{Na}$ cadeia de relações entre os que produzem e os que consomem existem distanciamentos e estão destituídos de sentido das vivências da coletividade, pilar e razão de ser das inter-relações de outrora. São ações automatizadas em todos os seus seguimentos. Trata-se, portanto, de um sistema de divisão de tarefas que transfere para outros o propósito da atividade.

Onde tudo é considerado mercadoria, também a arte se subordina às leis da competição, principalmente pelas seguintes características: visa o lucro advindo da exploração da atividade alheia e naturalizando o individualismo.

É possível perceber que arte e sociedade não são relações que ocorrem isoladamente, mas nas entranhas de inúmeros outros contatos e contextos entre os seres humanos. Entretanto, quando entra em cena a arte como mercadoria, estamos adentrando outra discussão: o tempo, ou melhor, o tempo de trabalho. Após o trabalho, aqui entendido como "a condição natural da existência humana" (MARX, p. 2008, p. 62), existe o tempo livre que é utilizado para repor a energia desprendida e ao convívio social, circunstâncias ideais para a arte. É com este "tempo livre" que decididamente não podemos mais contar, por estar seriamente comprometido com as atuais circunstâncias da sociedade. Marx (2008, p. 55) expõe que "o tempo de trabalho é a expressão quantitativa do trabalho", quando a produção das mercadorias é convertida em tempo de trabalho e este em valor de troca, o tempo livre que outrora era dedicado para repor a energia vital e ao convívio social passa a ser comprometido na tentativa de equiparação das diferenças sociais. Estas são algumas considerações que podem explicar sobre a gradativa ausência da arte na vida das pessoas. Marx (2008, p. 57) afirma que

O tempo de trabalho representado no valor de troca é o tempo de trabalho do indivíduo, mas do indivíduo que não se distingue dos demais indivíduos, enquanto realizam um trabalho igual, de tal maneira que o tempo de trabalho gasto por um para produzir uma determinada mercadoria, é o tempo de trabalho necessário que qualquer outro empregaria em produzir a mesma mercadoria. É o tempo de trabalho do indivíduo, mas não é seu tempo de trabalho, posto que é o tempo de trabalho comum a todos e, portanto, é indiferente que seja o tempo de trabalho de tal ou qual indivíduo.

Portanto, defender a importância da arte na vida das pessoas é uma questão soberana que reflete diretamente no processo de humanização. O tempo dedicado à atividade artística enriquece as relações humanas, no exercício de reflexão sobre a própria subjetividade.

\section{A captura da arte sob a lógica Capitalista}

Geralmente quando nos referimos ao Capitalismo, nos vêm em primeiro plano a Revolução Industrial e suas conseqüências que influenciaram (e influenciam) todos os aspectos da existência humana. No âmago desta questão, encontra-se “o trabalho como elemento central e de grande importância para o entendimento do individuo na vida social" (CARDOSO, 2011, p. 266). Neste novo cenário, as 
necessidades de subsistência do artífice e sua família não dependem mais do sistema do mecenato; o mecena de autrora, a partir de então, converte-se ao novo sistema de relações sociais, políticas e econômicas em que tudo passa a ser elemento potencial do mercado emergente. A margem de lucro exponencial e, consequentemente, uma possível fonte acumulativa de riqueza privada, configurando-se, portanto, como propriedade capitalista, totalmente naturalizada.

Contudo, iremos abordar sobre o Capitalismo a partir de um acontecimento anterior e, com isso daremos continuidade às exposições. O enfoque, então, se dará, evidenciando a tomada de Constantinopla em 30 de maio de 1483 (RUNCIMAN, 1965). Este evento teve como um de seus efeitos a expansão marítima culminando na viagem de circunavegação ${ }^{4}$, que favoreceu descobertas de novas fronteiras e civilizações, até então desconhecidas. Estas novas descobertas de áreas geográficas trazem novos conhecimentos de povos mais avançados, no âmbito político, econômico, filosófico e artístico. No decurso deste grande acontecimento na história da humanidade, estando os portugueses na vanguarda destes "descobrimentos", novos mundos, dentre estes, o Brasil, em 22 de abril de 1500, serão incorporados e explorados, sob o pretexto de "colonização" a serviço da propagação do Cristianismo. Nos desdobramentos destes acontecimentos, os navegantes portugueses chegam à Índia e o mundo passa a ser uma grande rota de confluências e trocas mercantis. A partir de então, o caminho para a consolidação da denominada "globalização" ocorre a favor daqueles que penetraram primeiro nestes ciclos de viagens exploratórias.

Na contemporaneidade, com a tendência de expansão do Capitalismo, no sentido de subordinar e condicionar as práticas humanas aos ideais hegemônicos restritos, obtém, na expansão geográfica fenomenal, um privilégio que dificilmente poderá ser superado. É neste contexto mais amplo, sob a lógica capitalista, que a arte também será subordinada, para então servir de objetivação, controlada e disposta a serviço de ideologias que lutam para manutenção dos mecanismos de controle. Apontando as engrenagens invisíveis destes mecanismos, Chauí (2006, p. 76) expõe como exemplo a burocratização estatal. No Brasil, esta burocratização se impõe desde tempos imemoriais:

De fato, a burocracia opera fundada em três princípios: a hierarquia do mando e da obediência, que define os escalões do poder; o segredo do cargo e da função, que garante poderes e controle dos graus superiores sobre os inferiores; a rotina dos hábitos administrativos que, por definição, são indiferentes à especificidade do objeto administrado.

Para Chauí (2006, p. 65), "numa perspectiva democrática, as prioridades são claras: trata-se de garantir direitos existentes, criar novos direitos e desmontar privilégios". Contudo, nas opções de tendências de política pública cultural, no Brasil, Chauí identifica três tipos - a cultura oficial, a populista e a neoliberal. Estas tipologias descritas, cada uma a sua maneira, reflete o autoritarismo em forma de controle estatal, sendo que, argumenta a autora, o "Estado não é produtor de cultura” (CHAUÍ, 2006).

Portanto, de maneira mais abrangente, o que podemos considerar como cultura, parte do princípio daquilo que consideramos como o oposto a natureza. Sendo cultura, portanto, a transformação da natureza pela intencionalidade da ação humana. Pensar em Cultura, a partir disto, pressupõe que "a própria ideia de natureza torna-se um objeto cultural", conclui Chauí (2006, p. 105). 
As atuais condições da existência humana estão diretamente relacionadas ao domínio da natureza e, conseguinte avanço da cultura, tendo como principal mediadora deste processo, o trabalho. Enquanto a natureza esquiva-se da ação humana, a Cultura realiza-se através da ação humana e intencionalidade de transformação da natureza, através do trabalho:

[...] pelo trabalho os homens não transformam simplesmente a natureza, mas a humanizam, pois um produto do trabalho exprime a subjetividade do produtor, que nega a naturalidade do objeto ao imprimir-lhe sua vontade, seu desejo e sues fins (...) com o trabalho, a cultura surge como desnaturalização da natureza (CHAUÍ, 2006, p. 109).

A arte como forma de cultura ocorre quando é produzida através da "humanização ou subjetivação da natureza pelo trabalho" (CHAUÍ, 2006), e se distingue da arte como objeto de consumo em massa, guiada pela reprodutividade alienante, individualista altamente concentrada na recepção de lucro, advindo da exploração alheia. É, pois, necessária a clara distinção de que a arte serve ao processo de humanização e, assim sendo, não pode ser reduzida a mera condição de transformação em mercadoria. Portanto, a Cultura dada como uma totalidade “[...] é, pois, a maneira pela qual os humanos se humanizam e, pelo trabalho, desnaturalizam a natureza por meios de práticas que criam a existência social, econômica, política, religiosa, intelectual e artística” (CHAUÍ, 2006, p. 113).

\section{Conclusões}

Existem várias discussões acerca da importância da arte na vida das pessoas. Nesta produção expomos algumas considerações iniciais a partir da perspectiva do marxismo. Na busca por referências, considerando a temática arte, ainda são poucas as produções que se isentam de particularizar determinada expressão artística. Esta fragmentação em várias disciplinas faz desvanecer a visão da arte como totalidade, comprometendo a arte em sua dimensão humana e cultural.

Entretanto, a partir das exposições apresentadas, evidencia-se que a arte é inerente a todo ser humano, sendo ou não artífice por ofício. A arte é uma atividade potencialmente humana e humanizadora, outrora vivenciada coletivamente através de rituais relacionados à magia. Referenciando-nos com base na vertente teleológica de Aristóteles, conduzimos uma reflexão sobre o sentido desta magia da arte. Constatamos que este sentido de magia foi uma necessidade humana que respondeu satisfatoriamente como solução transitória diante de um mundo real inexplorado, enquanto a ciência ainda não havia se consolidado.

A capacidade imagética do ser humano tem um limite: a sua própria realidade ressignificada em função da observação do mundo socialmente constituído. $O$ valor da arte como patrimônio da humanidade é anterior à reputação do artista, embora este tenha seus méritos reconhecidos.

$\mathrm{Na}$ trajetória das comunidades primitivas, encontravam-se, prioritariamente, as atividades relacionadas à manutenção da existência humana individual e do grupo, e dependia da observação, compreensão e posterior domínio sobre a natureza circundante. A arte não é apenas para o vínculo de socialização, quando cessam as necessidades básicas de subsistência. É objetivada e potencialmente 
humana, que advém da capacidade de abstração da realidade particular e coletiva, utilizando predominantemente alguma forma peculiar de expressão.

Portanto, a atividade humana que denominamos arte é um processo cognitivo, afetivo e operacional que demanda certo período de tempo particular, onde ocorre o exercício crítico e reflexivo do pensar, sentir e agir no mundo. A realidade do mundo não é estática, pois a ação humana gera movimento, que advém da necessidade real que urge buscar respostas efetivas para as transformações necessárias.

A principal discussão, ora apresentada, remete às exposições de Karl Marx sobre a questão tempo, ou melhor, tempo de trabalho. Marx discute as bases epistemológicas necessárias para a compreensão sobre os mecanismos que precarizam e subordinam o uso do tempo à lógica do capital. Esta é uma discussão importante na atualidade, pois sendo a arte uma atividade que demanda tempo, ela não subsiste em circunstâncias restritivas ou hostis, onde a ação humana não tenha um sentido para a transformação.

A teoria de Marx oferece condições sólidas para amparar sistemática e cientificamente os fundamentos para várias áreas do conhecimento humano. A arte, com o seu poder de representar concretamente uma intenção que é abstrata, sustenta a esperança para a ação transformadora da realidade, superando as adversidades que se apresentarem para o indivíduo e nas suas relações com o Outro. Todo o processo de comprometimento do fazer artístico implica necessariamente em tempo de contatos humanos, no sentido de convívio, comunicação e contigüidade.

A expansão do capitalismo vai além de fronteiras geográficas e seus desdobramentos. Esta expansão desenrola uma série de subterfúgios cuja grande perda se dá nos contatos e nas relações humanas. Uma grande multidão pode ser apenas a confluência de pessoas imersas em suas próprias individualidades. Ao negligenciar a importância da arte, a subjetividade humana se desconstrói. A marca indelével de cada ser humano não é observável e, o Outro, portanto, é estranhável. Nisto, não percebemos um pouco de nós mesmos no contributo da totalidade e, nesta totalidade, perdemos a percepção de nossa própria contribuição. O perigo, portanto, está na facilidade com a qual vivemos tão confortáveis abandonando, cada vez mais, a iniciativa de fazer da arte uma necessidade de expressão que possa ser compreendida, como visão de mundo, homem e sociedade.

\section{Referências}

ALTHUSSER, Louis. Écrits philosophiques et politiques. Coletânea de textos; Tomo II. Org. François Matheron. Paris, Éditions STOCK/IMEC, 1997, p. 561-578. Trad. Danilo Enrico Martuscelli. ARISTÓTELES. Poética. 2a ed. São Paulo: Ars Poética, 1993.

BENJAMIN, Walter. A obra de arte na época de sua reprodutibilidade técnica. In: ADORNO et al. Teoria da Cultura de massa. Trad. de Carlos Nelson Coutinho. São Paulo: Paz e Terra, 2000.

CARDOSO, Luís Antonio. A categoria do trabalho no capitalismo contemporâneo. Revista de Sociologia da USP, v. 23, n. 2, Nov. 2011. 
COTRIM, Ana. Marx e a épica. Communicare: revista de pesquisa do Centro Interdisciplinar de Pesquisa. Faculdade Cásper Líbero. - v. 12, nº 2 (2012). São Paulo: Faculdade Cásper Líbero.

DESCARTES, René. Compendio de Música. Introdução Ángel Gabilongo; tradução Primitiva Flores e Carmen Gallardo. Madrid: Editorial Tecnos, 2001 - (Coleção Metropolis).

DUARTE, Newton. ABREU, Thiago Xavier de. Sobre o sentido político do ensino de música na educação escolar: das relações entre a arte e a realidade objetiva. LINHAS (FLORIANÓPOLIS. ONLINE), v. 20, p. 12-35, 2019.

EPOPÉIA GREGA. Dicionário da Academia de Poetas Americanos. Disponível em:<

https://poets.org/text/epic-poetic-form>. Acessado em: 17/06/2019.

FISCHER, Ernst. A Necessidade da Arte. Rio de Janeiro: Zahar, 1959. Tradução: Leandro Konder.

HARNECKER, Marta. Os conceitos elementais do materialismo histórico. São Paulo: Ed. Global, 1971.

HARTLEY, John. Teleology: studies in television. First published 1992, by Routledge. Simultaneously London and New York.

JOHNSON, Monte Ramone. Aristotle on Teleogy. Oxford/UK: Claredon Press, 2005.

KLEIN, Richard G.; BLAKE, Edgar. O despertar da cultura. Rio de Janeiro, Jorge Zahar Editor, 2005.

KOSIK, Karel. Dialética do Concreto. $2^{\text {a }}$ ed. Rio de Janeiro: Paz e Terra, 1969.

LUKÁCS, G. Introdução a uma Estética Marxista. Rio de Janeiro: Editora Civilização Brasileira, 1968.

MARTINS, M.F. Práxis e “catarsis” como referências avaliativas das ações educacionais das ONG’s, dos sindicatos e dos partidos políticos. Avaliação, v.16, n.3, p.533-558, 2011.

MARX, K. Manuscritos econômico-filosóficos de 1844. Tradução de Jesus Ranieri. São Paulo: Boitempo, 2004. MARX, K. Grundrisse. Tradução de Mario Duayer e Nélio Schneider. São Paulo: Boitempo; Rio de Janeiro: Ed. UFRJ, 2011.

MARX, K. Contribuição à Crítica da Economia Política. Tradução e Introdução de Florestan Fernandes. São Paulo: Expressão Popular, 2009.

MOLINO, Jean. Facto Musical e Semiologia da Música. In J. J. Nattiez, Umberto Eco, Nicolas Ruwet, Jean Molino. Semiologia da música. Lisboa: Vega, (s/d).

ÖSTERBLOM, H., M. SCHEFFER., WESTLEY, F. R., VAN ESSO, M. L., MILLER, J., BASCOMPTE, J. Ecology and Society. Vol. 20, No. 4 (Dec 2015). Disponivel em:<https://www.jstor.org/journal/ecologysociety>. Consultado em: 06/Jul/2018.

QUEIROZ, A. Sobre o conceito de catarse na Poética de Aristóteles. Revista Entrelinhas, v. 1, p. 1, 2013.

SCHEFFER, M., M. BAAS e T.K. BJORDAM ( 2017). Teaching originality? Common habits behind creative production in science and arts. Ecology and Society, 22 (2), [29]. Disponível em :< https://pure.uva.nl/ws/files/15015297/ES_2017_9258.pdf >. Consultado em: 06/Jul./2018.

TROJAN, Rose Meri. A arte e a humanização do homem: afinal de contas, para que serve a arte? Educ. rev. Curitiba, n. 12, p. 87-96, Dez. de 1996. Consultado em: 31 de maio de 2018.

RUNCIMAN, Steven. The fall of Constantinopla, 1482. Cambridge: University Press, 1965. 


\section{Notas:}

${ }^{1}$ Universidade Federal de São Carlos. Possui Mestrado em Educação pelo PPGed-So Universidade Federal de São Carlos (2019). Graduação em Licenciatura em Música pela Universidade Católica do Salvador (1992). Graduanda do Curso de Licenciatura em Educação Especial da Universidade Federal de São Carlos (2014) e atualmente graduanda do Curso de Licenciatura em Pedagogia da UFSCar campus Sorocaba. Pesquisadora no Núcleo de Estudos e Pesquisas em Direito à Educação-Educação Especial - (www.nepedeees.ufscar.br).Tem experiência na área de Educação, com ênfase em Música e Educação Especial, atuando principalmente no seguinte tema: educação musical de Surdos. ORCID: http://orcid.org/0000-0002-5469-1703 Email: mercia1565@hotmail.com

2 Universidade Federal de São Carlos Possui graduação em Pedagogia pela Universidade Estadual de Campinas (2002). É Doutora em Educação pelo Programa de Pós-Graduação da Faculdade de Educação da Unicamp. Possui pós-doutorado em Educação pela Universidade do Vale do Sapucaí - UNIVAS, pelo PNPD/CAPES. Atualmente é professora Adjunta do Departamento de Ciências Humanas e Educação da UFSCar, campus Sorocaba, Líder do Grupo de Estudos e Pesquisas Historia, Sociedade e Educação no Brasil - HISTEDBR - GT UFSCar-So, pesquisadora do Grupo de Estudos e Pesquisas HISTEDBR - GT Unicamp, pesquisadora do NEPHE, Núcleo de Estudos e Pesquisas Ética, Política e História da Educação, da UNIVÁS e pesquisadora do Grupo de Pesquisa Teorias e Fundamentos da Educação - GPTeFE, UFSCar, campus Sorocaba. Atuou como Diretora Pedagógica na Secretaria Municipal de Educação de Limeira/SP, Professora Doutora I (substituta) da Faculdade de Educação da Unicamp e professora dos cursos de Especialização em Educação no Centro Universitário Salesiano - UNISAL. Tem experiência na área de Educação, principalmente nos seguintes áreas/temas: história da educação, política e gestão educacional, formação de professores, trabalho educativo, concepções pedagógicas. ORCID: http://orcid.org/0000-0002-86820952 Email: lucscoutinho@gmail.com

3 Epopéia Grega: é uma narrativa longa, muitas vezes em tamanho de livro, em verso que reconta a jornada heróica de uma única pessoa, ou grupo de pessoas. Elementos que tipicamente distinguem épicos incluem feitos sobre-humanos, aventuras fabulosas, linguagem altamente estilizada e uma mistura de tradições líricas e dramáticas.

4 Circunavegação: viagem marítima à roda do mundo. Dicionário Priberam da Língua Portuguesa. Disponível em:<https://dicionario.priberam.org/Viagem. Consultado em 18-06-2019].

Recebido em: 03.10.2019

Publicado em: 